\title{
AVALIAÇÃO DA QUALIDADE MICROBIOLÓGICA DE LEITE CRU REFRIGERADO OBTIDO DE PROPRIEDADES RURAIS DA ZONA DA MATA MINEIRA
}

\author{
Priscila Lima Sequetto ${ }^{1 *}$, Amanda dos Santos Antunes ${ }^{1}$, Athos Sampaio Nunes ${ }^{1}$, Lorena Kimberly Silva \\ Alcantara ${ }^{1}$, Mariana de Almeida Rosa Rezende ${ }^{1}$, Miriam Aparecida de Oliveira Pinto ${ }^{2}$, Gleide Gatti \\ Fontes $^{2}$, Humberto Moreira Húngaro ${ }^{2}$
}

\begin{abstract}
RESUMO - A cultura regional da atividade leiteira de Minas Gerais, principalmente na forma de obtenção, coleta, armazenamento e transporte do leite cru pode interferir negativamente na qualidade desta matériaprima e, consequentemente, nos seus derivados lácteos. Este estudo analisou a qualidade microbiológica influenciada pelos tipos de ordenha e de armazenamento do leite cru. Foram investigados 10 tanques de expansão em propriedades rurais da Zona da Mata Mineira, cujas amostras foram coletadas em abril de 2015 e encaminhadas ao Laboratório de Análise de Alimentos e Águas da Universidade Federal de Juiz de Fora, em Juiz de Fora, MG. As amostras foram avaliadas quanto à presença de coliformes totais, Escherichia coli, contagem de bactérias aeróbias mesófilas e psicrotróficas. Os resultados das contagens de bactérias aeróbias mesófilas foram avaliados conforme o padrão preconizado pela Instrução Normativa 62/2011 do MAPA. Das amostras analisadas, $80 \%$ apresentaram coliformes totais, $60 \%$ continham $E$. coli, $40 \%$ estavam em desacordo com o padrão legal de bactérias aeróbias mesófilas, e $10 \%$ excederam a $10^{6} \mathrm{UFC} / \mathrm{mL}$ de bactérias psicrotróficas. As médias das contagens de bactérias aeróbias mesófilas e psicrotróficas em amostras coletadas em tanques comunitários $(6,41 \log$ e $6,30 \mathrm{UFC} / \mathrm{mL})$ e em ordenha manual $(5,87$ e 5,50 $\log \mathrm{UFC} / \mathrm{mL})$ foram superiores àquelas obtidas em tanques individuais $(4,35 \mathrm{e}$ 3,91 log UFC/mL) e ordenha mecânica (4,37 e 4,05 log UFC/mL), respectivamente. Esses resultados indicam falhas em condições higiênico-sanitárias na obtenção e armazenamento do leite cru na maioria dos tanques analisados. É evidente a necessidade de orientações técnicas aos produtores rurais desta região para promover melhorias em todos os aspectos na produção leiteira.
\end{abstract}

Palavras chave: alimentos de origem animal, análise microbiológica, leite, tanques de expansão.

\section{MICROBIOLOGICAL QUALITY EVALUATION OF RAW REFRIGERATED MILK OBTAINED FROM RURAL PROPERTIES OF ZONA DA MATA MINEIRA}

\begin{abstract}
The regional culture of dairy activity in Minas Gerais, mainly in the form of obtaining, collecting, storing and transporting raw milk can negatively interfere in the quality of this raw material and, consequently, in its dairy products. This study analyzed the microbiological quality influenced by the types of milking and storage of raw milk. Ten expansion tanks were investigated in rural properties in the Zona da Mata Mineira, whose samples were collected in April 2015 and sent to the Laboratório de Análise de Alimentos e Águas of Universidade Federal de Juiz de Fora, in Juiz de Fora, MG. The samples were evaluated for the presence of total coliforms, Escherichia coli, counting of mesophilic and psychrotrophic aerobic bacteria. The results of mesophilic aerobic bacteria counts were evaluated according to the standard recommended by MAPA Instrução Normativa 62/2011. Of the analyzed samples, $80 \%$ presented total coliforms, $60 \%$ contained E. coli, $40 \%$ were in disagreement with the legal standard of mesophilic aerobic bacteria, and $10 \%$ exceeded $10^{6} \mathrm{CFU}$
\end{abstract}

\footnotetext{
${ }^{1 *}$ Endereço para correspondência: 1 Laboratório de Bromatologia e Microbiologia de Alimentos, Departamento de Farmácia, Universidade Federal de Juiz de Fora - Campus Governador Valadares. Rua Israel Pinheiro, 2000, Bairro Universitário, Governador Valadares, MG, Brasil. CEP: 35020-220. Tel: (33) 3301-1000 / (33) 99975-7404. E-mail: priscila.sequetto@ufjf.edu.br

${ }^{2}$ Laboratório de Análises de Alimentos e Águas, Departamento de Ciências Farmacêuticas, Universidade Federal de Juiz de Fora - Campus Juiz de Fora. Rua José Lourenço Kelmer, s/n. Campus Universitário - São Pedro, Juiz de Fora, MG, Brasil. CEP: 36036-330.
} 


\begin{abstract}
I mL of psychrotrophic bacteria. The mean counts of mesophilic and psychrotrophic aerobic bacteria in samples collected in community tanks (6,41 log and 6,30 CFU/ $\mathrm{mL})$ and manual milking (5,87 and 5,50 $\log C F U / m L)$ were higher than those obtained in individual tanks (4,35 and 3,91 $\log C F U / m L)$ and mechanical milking (4,37 and 4,05 $\log C F U / m L)$, respectively. These results indicate faults in hygienicsanitary conditions in the collection and storage of raw milk in most of the analyzed tanks. There is a clear need for technical guidance to farmers in this region to promote improvements in all aspects of milk production.
\end{abstract}

Keywords: milk, expansion tanks, microbiological analysis, food of animal origin.

\section{INTRODUÇÃO}

O leite é por natureza um alimento rico em nutrientes contendo proteínas, carboidratos, gorduras, vitaminas e sais minerais. A composição do leite pode variar em função de vários fatores, incluindo espécie, fase de lactação, época do ano e alimentação da lactante (Guerreiro et al., 2005). Segundo a Instrução Normativa $n^{\circ} 62$, de 29 de dezembro de 2011 entende-se por leite, sem outra especificação, o produto oriundo da ordenha completa e ininterrupta, em condições de higiene, de vacas sadias, bem alimentadas e descansadas, enquanto que o leite de outros animais deve denominar-se segundo a espécie de que proceda (Brasil, 2011). O leite de vaca apresenta variações de 82,8 a $85,9 \%$ de água, 2,2 a $4,2 \%$ de proteínas, 3,7 a $5,1 \%$ de lactose, 2,3 a $5,3 \%$ de gordura e 0,51 a $0,77 \%$ de sais minerais (Walstra et al., 2006).

No Brasil, o leite é um dos principais produtos agropecuários, devido principalmente à sua elevada produção, comercialização e consumo. A grande importância deste alimento está relacionada ao seu valor econômico e nutricional, pois, além de gerar empregos e renda, o leite desempenha um importante papel na alimentação humana sendo recomendado em todas as fases da vida, principalmente para atingir a adequação diária de cálcio, um nutriente fundamental para a formação e manutenção da estrutura óssea, entre outras funções no organismo (Martins et al., 2016; Brasil, 2006).

A produção de leite é uma das atividades mais antigas e de maior destaque no desenvolvimento do agronegócio brasileiro. Segundo dados do Instituto Brasileiro de Geografia e Estatística (IBGE), em 2015 a produção nacional chegou a 24,05 bilhões de litros. Neste cenário, o estado de Minas Gerais destaca-se em produção, contribuindo com $26,8 \%$ do total de leite produzido em 2015 no país (IBGE, 2015a). Este estado também foi um dos principais exportadores de leite in natura em 2014, cujo destino da produção foi Chile, Bolívia, Sri Lanka, África do Sul, Angola e Estados Unidos da América (IBGE, 2015b).

A atividade leiteira brasileira é muito diversificada e caracteriza-se por diferentes sistemas de produção, incluindo tipo de manejo e raça dos animais, especialização ou não na ordenha e armazenamento do leite na fazenda, volume produzido e condição de renda dos produtores (Souto et al., 2009). A melhoria das condições de produção, obtenção, estocagem, transporte e acondicionamento nas plantas de processamento são etapas fundamentais para garantir a qualidade do leite e de seus derivados (Cerqueira et al., 2015).

A estocagem do leite cru refrigerado na fonte de produção iniciou-se no Brasil, na década de 90, sendo regulamentado pelo Ministério da Agricultura, Pecuária e Abastecimento (MAPA) por meio da Instrução Normativa $\mathrm{n}^{\circ} 51$, de 18 de setembro de 2002, retificada pela Instrução Normativa $n^{\circ} 62$, de 29 de dezembro de 2011, que determinam normas na produção, identidade e qualidade de leites pasteurizado e cru refrigerados, além de regulamentar a coleta de leite cru refrigerado e seu transporte a granel (Brasil, 2002; Brasil, 2011). Essa prática reduz perdas econômicas por atividade acidificante de bactérias mesófilas, mas permite a seleção de bactérias psicrotróficas relacionadas a problemas tecnológicos e econômicos na indústria de laticínios (Fonseca \& Santos, 2000). A qualidade do produto final está diretamente relacionada à carga microbiológica do leite ao chegar à indústria beneficiadora (Guerreiro et al., 2005). Diante do exposto, o presente estudo teve como objetivo avaliar a qualidade microbiológica de amostras de leite cru refrigerado, armazenado em tanques de expansão de propriedades rurais da Zona da Mata Mineira, bem como, a influência dos tipos de ordenha e de armazenamento em tanques comunitários e individuais. 


\section{MATERIAL E MÉTODOS}

\subsection{Amostragem}

A coleta das amostras para a avaliação da qualidade do leite cru refrigerado foi realizada no mês de abril de 2015 em propriedades rurais que forneciam esta matéria-prima para uma Cooperativa Agropecuária na Zona da Mata de Minas Gerais, que recebia em média leite de 100 propriedades. Foram recolhidas amostras de 10 tanques de expansão de propriedades rurais que constituíam uma das rotas percorridas pelo caminhão de coleta, seguindo os critérios de uma amostragem não probabilística por conveniência.

As amostras foram coletadas, armazenadas em frascos esterilizados e identificadas. Cada amostra foi identificada por uma letra seguindo a ordem alfabética de A a J. As amostras A, B, C, D, E e F são provenientes de tanques de expansão individuais e com ordenha mecânica. No caso das amostras H e I, os tanques são comunitários e seus produtores utilizam a ordenha manual para obtenção da matéria prima, a amostra $\mathrm{G}$ é resultado de uma ordenha também manual, mas o tanque de expansão é individual. Já a amostra J foi coletada de um tanque comunitário onde a matériaprima é obtida pelos produtores tanto por ordenha manual quanto mecânica. Após a coleta as amostras foram transportadas em temperatura de refrigeração até o Laboratório de Análise de Alimentos e Águas (LAAA) da Universidade Federal de Juiz de Fora, em Juiz de Fora, Minas Gerais, para realização das análises microbiológicas.

\subsection{Análises microbiológicas do leite cru refrigerado}

\subsubsection{Contagem de bactérias aeróbias mesófilas}

Para a quantificação de bactérias aeróbias mesófilas foram realizadas contagens padrão em placas com incubação a $35 \pm 1{ }^{\circ} \mathrm{C} / 48 \mathrm{~h}$ pelo método de "pour plate", em Ágar Padrão para Contagem (PCA), em duplicata, em diferentes diluições. Após o período de incubação, as colônias foram contadas para expressão dos resultados utilizando o limite de contagem de 25 a 250 UFC por placa (Silva et al., 2010).

\subsubsection{Contagem de bactérias psicrotróficas}

Para a quantificação de bactérias psicrotróficas foram feitas as contagens padrão em placas com incubação a $7{ }^{\circ} \mathrm{C}$, durante 10 dias, em Ágar Padrão para Contagem (PCA), em duplicata, em diferentes diluições. Após o período de incubação, as colônias foram contadas utilizando os mesmos critérios descritos anteriormente (Silva et al., 2010).

\subsubsection{Análises de coliformes totais e Escherichia coli}

As análises de coliformes totais e Escherichia coli foram realizadas por meio da técnica de Presença - Ausência (PA) utilizando Caldo Lauril Sulfato Triptose (LST) em tubos de ensaio contendo tubos de Durham invertidos e inóculo de $1 \mathrm{~mL}$ das amostras de leite cru. Os tubos inoculados foram incubados a $35^{\circ} \mathrm{C}$ por $24 /$ 48 horas em estufa bacteriológica. Os tubos com reação presuntiva positiva, evidenciada pela produção de gás, foram submetidos ao teste confirmatório em Caldo Lactose Verde Brilhante Bile 2\% (CLVBB). Para a confirmação de E. coli as amostras positivas para coliformes totais foram repicadas em tubos contendo Caldo Ec-mug, incubadas a $35^{\circ} \mathrm{C}$ por 24 horas, e avaliadas quanto à presença de fluorescência em luz UV a 365 nm (Silva et al., 2010).

\subsection{Análises estatísticas}

Os dados das contagens de bactérias aeróbias mesófilas e de psicrotróficas de cada tanque de expansão foram analisados por meio de Análise de Variância (ANOVA) e teste de Duncan ao nível de significância de 5\%. A influência do tipo de ordenha e condição de armazenamento sobre a qualidade microbiológica do leite cru foi avaliada pelo teste t de Student com nível de significância de 5\%.

\section{RESULTADOS E DISCUSSÃO}

\subsection{Bactérias aeróbias mesófilas}

A análise revelou que em quatro das 10 amostras coletadas, sendo elas C, H, I e J (Tabela 1), as contagens de bactérias aeróbias mesófilas estavam fora dos padrões microbiológicos estabelecidos na IN 62 de 29 de dezembro de 2011 do MAPA, que considera como limite o valor de $3 \times 10^{5} \mathrm{UFC} / \mathrm{mL}$, correspondendo a aproximadamente 5,47 na escala logarítmica (Brasil, 2011).

A avaliação microbiológica do leite cru pode determinar falhas em sua qualidade apontando problemas em relação à adoção de práticas higiênico-sanitárias inadequadas em utensílios e equipamentos utilizados na ordenha, no armazenamento e na sua refrigeração durante a estocagem. Estas condições contribuem para 
Tabela 1 - Médias dos logaritmos dos números de unidades formadoras de colônias (UFC/mL) de bactérias aeróbias mesófilas nas amostras de leite cru em função do tipo de ordenha e armazenamento

\begin{tabular}{|c|c|c|c|c|}
\hline \multirow{2}{*}{ AMOSTRA } & \multirow{2}{*}{ ORDENHA } & \multirow{2}{*}{ TANQUE } & MESÓF. & MESÓF. \\
\hline & & & Média UFC/mL & $\log \mathrm{UFC} / \mathrm{mL}$ \\
\hline A & MECÂNICA & INDIVIDUAL & $9,20 \times 10^{3}$ & $3,96^{\mathrm{g}}$ \\
\hline $\mathrm{B}$ & MECÂNICA & INDIVIDUAL & $3,64 \times 10^{4}$ & $4,56^{\mathrm{e}}$ \\
\hline $\mathrm{C}$ & MECÂNICA & INDIVIDUAL & $2,09 \times 10^{6}$ & $6,32^{\mathrm{c}}$ \\
\hline $\mathrm{D}$ & MECÂNICA & INDIVIDUAL & $2,10 \times 10^{4}$ & $4,32^{\mathrm{f}}$ \\
\hline $\mathrm{E}$ & MECÂNICA & INDIVIDUAL & $1,89 \times 10^{3}$ & $3,27^{\mathrm{I}}$ \\
\hline $\mathrm{F}$ & MECÂNICA & INDIVIDUAL & $6,00 \times 10^{3}$ & $3,77^{\mathrm{h}}$ \\
\hline G & MANUAL & INDIVIDUAL & $1,82 \times 10^{4}$ & $4,26^{\mathrm{f}}$ \\
\hline $\mathrm{H}$ & MANUAL & COMUNITÁRIO & $3,28 \times 10^{6}$ & $6,51^{b}$ \\
\hline I & MANUAL & COMUNITÁRIO & $1,30 \times 10^{7}$ & $7,11^{\mathrm{a}}$ \\
\hline $\mathrm{J}$ & MISTA & COMUNITÁRIO & $4,10 \times 10^{5}$ & $5,61^{\mathrm{d}}$ \\
\hline
\end{tabular}

*Amostras seguidas pela mesma letra não diferem estatisticamente entre si em relação à contagem de micro-organismos pelo teste de Duncan ao nível de significância de 5\%.

a obtenção de um produto de baixa qualidade associado ao crescimento de micro-organismos prejudiciais à qualidade e inocuidade do leite (Tebaldi et al., 2008; Souto et al., 2009).

O controle inadequado da temperatura do leite durante sua estocagem pode contribuir para a multiplicação de bactérias aeróbias mesófilas, uma vez que a refrigeração tem como objetivo controlar o desenvolvimento destes micro-organismos que em sua maioria, fermentam a lactose produzindo ácido láctico, causando acidificação do leite e comprometendo sua utilização na indústria (Fonseca \& Santos, 2000). A regulamentação da estocagem do leite cru sob refrigeração estabelecida pela IN 51 em 2002 garante o controle da multiplicação de bactérias aeróbias mesófilas e permite a melhor qualidade do produto. Em contrapartida, a refrigeração do leite permite o crescimento de bactérias psicrotróficas, onde a baixa temperatura proporciona um ambiente adequado para sua multiplicação.

As maiores contagens de bactérias aeróbias mesófilas foram observadas nas amostras coletadas em tanques comunitários, variando de $4,10 \times 10^{5}$ a $1,30 \times 10^{7} \mathrm{UFC} /$ $\mathrm{mL}$. Estes resultados sugerem que as práticas higiênicas adotadas não garantiram a qualidade do leite armazenado sob refrigeração, e que o uso de tanques comunitários, pode aumentar a possibilidade de contaminação. Nestas amostras, a contagem padrão bactérias aeróbias mesófilas não atendeu ao requisito microbiológico proposto pelo MAPA em vigor a partir de 01/07/2014, para as regiões Sul, Sudeste e Centro-Oeste, que é de $3 \times 10^{5} \mathrm{UFC} / \mathrm{mL}$ (Brito et al., 2003; Vidal-Martins et al., 2005).
A variação nas contagens de bactérias aeróbias mesófilas nas amostras coletadas em tanques individuais foi de $1,89 \times 10^{3} \mathrm{UFC} / \mathrm{mL}$ a $2,09 \times 10^{6} \mathrm{UFC} / \mathrm{mL}$, das quais apenas a amostra do produtor $\mathrm{C}$ apresentou contagem superior ao limite estabelecido pelo MAPA. A diferença de contagem observada entre as amostras individuais pode ser atribuída a vários fatores como: qualidade do leite cru (matéria-prima), da água utilizada na higienização dos equipamentos e deficiências no treinamento da mãode-obra empregada (Foschino et al., 1990; Bahout, 2000).

Ao analisar amostras de leite coletadas na Zona da Mata Mineira em 2005, Pinto et al. (2006) encontraram valores de contagem de micro-organismos aeróbios mesófilos que não estavam de acordo com a IN 51, vigente na época, cujo limite era de $1,0 \times 10^{6} \mathrm{UFC} / \mathrm{mL}$. Como a legislação vem se tornando cada vez mais exigente em relação aos padrões microbiológicos, os valores considerados superiores ao estabelecido por lei em 2005 continuam inadequados considerando o requisito microbiológico estabelecido pela IN 62 em 2011 (Brasil, 2011).

A diferença entre os tipos de ordenha torna-se visível ao se comparar os valores mínimos e máximos de bactérias aeróbias mesófilas em UFC/mL encontrados nas amostras de leite cru analisadas no presente estudo. As ordenhas mecânica e manual apresentaram valores mínimos de $1,89 \times 10^{3} \mathrm{UFC} / \mathrm{mL}$ e $1,82 \times 10^{4} \mathrm{UFC} / \mathrm{mL}$ e máximos de $2,09 \times 10^{6} \mathrm{UFC} / \mathrm{mL}$ e $1,30 \times 10^{7} \mathrm{UFC} / \mathrm{mL}$, respectivamente. A contagem da amostra coletada no tanque em que existiu a mistura de leite cru obtido tanto por ordenha manual quanto mecânica foi de 4,10 x $10^{5} \mathrm{UFC} / \mathrm{mL}$ (Tabela 1). 
De acordo com Martins e Lima (2013), as contagens de bactérias aeróbias mesófilas mais baixas em ordenha mecânica devem-se a forma de obtenção do leite que neste caso, é adquirido por meio de um sistema de circuito fechado e, após ser retirado do animal vai direto para o tanque de refrigeração. No entanto, a ordenhadeira, quando mal higienizada, pode se tornar um veículo para transmissão de micro-organismos, estando diretamente relacionada à contaminação do produto (Pinheiro \& Mosquim, 1991). Essa prática de circuito fechado diminui as chances de contaminação do leite quando comparada à ordenha manual, onde o ordenhador utiliza de baldes, por exemplo, para armazenar o leite durante um período, aumentando a exposição do produto a altas temperaturas beneficiando a multiplicação de aeróbios mesófilos.

A ordenha higiênica inicia-se com o estado sanitário dos animais, do ordenhador, das condições de ordenha, do equipamento usado na coleta e transporte do leite (Sommerhäuser et al. 2003). A higiene dos tetos é o fator mais importante no momento da ordenha, pois evita a exposição do leite a contaminações por microorganismos e sujidades, quer sejam provenientes do ambiente ou do ordenhador (Oliveira et al., 1999). A produção de leite no Brasil por pequenos produtores ocorre normalmente de forma rudimentar, sem a devida assistência por programas de extensão que envolvam práticas de higiene, melhorias da produção e condições financeiras para a aquisição de equipamento para a ordenha do leite, o que contribui para a utilização da ordenha manual sem os devidos cuidados higiênicos e, consequentemente, para a diminuição da qualidade do produto (Tavolaro et al., 2006).

\subsection{Psicrotróficos}

A contagem de bactérias psicrotróficas nas amostras de leite cru variou de $1,20 \times 10^{3}$ a $2,93 \times 10^{7} \mathrm{UFC} / \mathrm{mL}$ (Tabela 2). As amostras provenientes de tanques comunitários apresentaram as maiores contagens deste grupo de bactérias.

A elevada contaminação microbiana constatada nas amostras de leite cru refrigerado pode estar associada a procedimentos de higienização inadequados no sistema de produção, considerando que resíduos de leite constituem fontes de nutrientes para o crescimento de bactérias e formação de biofilmes. A carga microbiana também pode ser adquirida durante os processos que antecedem o resfriamento ou até mesmo proveniente do tanque de refrigeração se houver má higienização dos equipamentos ou utilização de água contaminada para a limpeza do sistema (Manfrin Scabin et al., 2012).

Não existe uma legislação específica para contagem de micro-organismos psicrotróficos no Brasil, no entanto, Fox (1989) afirma que bactérias psicrotróficas causam proteólise quando a população excede $10^{6} \mathrm{UFC} / \mathrm{mL}$. Pinto et al. (2006) mostraram que contagens de psicrotróficos superiores a $5 \times 10^{6} \mathrm{UFC} / \mathrm{mL}$ são consideradas impróprias para processamento, pois podem ter enzimas que causam problemas de deterioração em produtos lácteos e prejuízos econômicos. Desta forma, das amostras analisadas neste estudo apenas uma (amostra I) apresentou valor de bactérias psicrotróficas acima do limite reportado por estes autores como aceitável. Entretanto, outras três amostras $(\mathrm{C}, \mathrm{H} \mathrm{e} \mathrm{J})$ apresentaram contagens elevadas e próximas a $10^{6} \mathrm{UFC} / \mathrm{mL}$. Apesar da amostra I ser obtida por meio de ordenha manual, não é possível afirmar que o tipo de ordenha tenha influenciado nos níveis de contaminação por psicrotróficos, pois os outros dois resultados de ordenha manual investigados estavam dentro do estabelecido.

Bactérias psicrotróficas causam diversas alterações em leite e produtos lácteos como o ranço, amargor, sabor pútrido de estragado (Garboggini \& Gallo, 1998). O desenvolvimento destas bactérias pode estar relacionado à má higienização ou à falta de um sistema de refrigeração adequado na estocagem. Como neste trabalho, são comuns aos produtores três tipos de ordenha (manual, mecânica e mista) e também dois tipos de tanques (individual e comunitário), a higienização inadequada pode comprometer a qualidade do leite favorecendo o crescimento bacteriano, principalmente na ordenha manual e em tanques comunitários, pelo fato de este tipo de ordenha não usar de técnicas modernas como a mecânica e por haver mistura de leite de outros produtores, o que não ocorre em tanques individuais. Verificamos que das amostras analisadas, o leite obtido do tanque I foi o que mostrou ser de qualidade microbiológica inferior apresentando o maior número de bactérias aeróbias mesófilas e de psicrotróficas. Tal fato pode ser caracterizado pela ordenha manual, falhas higiênico-sanitárias e, também, pelo tanque ser comunitário recebendo leite cru de diferentes produtores. $\mathrm{Na}$ ordenha manual o ordenhador tem papel destacado, porque tanto ele pode reduzir a contaminação microbiana do leite, quanto pode aumentá-la. A contaminação levada pelo ordenhador é influenciada pelos seus hábitos 
Tabela 2 - Médias dos logaritmos dos números de unidades formadoras de colônias (UFC/mL) de bactérias psicrotróficas nas amostras de leite cru em função do tipo de ordenha e armazenamento

\begin{tabular}{|c|c|c|c|c|}
\hline \multirow{2}{*}{ AMOSTRA } & \multirow{2}{*}{ ORDENHA } & \multirow{2}{*}{ TANQUE } & Psicrotróficos & Psicrotróficos \\
\hline & & & Média UFC/mL & $\log \mathrm{UFC} / \mathrm{mL}$ \\
\hline A & MECÂNICA & INDIVIDUAL & $1,95 \times 10^{3}$ & $3,29^{\mathrm{fg}}$ \\
\hline $\mathrm{B}$ & MECÂNICA & INDIVIDUAL & $1,43 \times 10^{4}$ & $4,15^{\mathrm{de}}$ \\
\hline $\mathrm{C}$ & MECÂNICA & INDIVIDUAL & $1,70 \times 10^{5}$ & $5,23^{\mathrm{c}}$ \\
\hline $\mathrm{D}$ & MECÂNICA & INDIVIDUAL & $1,95 \times 10^{3}$ & $3,29^{f}$ \\
\hline $\mathrm{E}$ & MECÂNICA & INDIVIDUAL & $1,94 \times 10^{4}$ & $4,29^{\mathrm{d}}$ \\
\hline $\mathrm{F}$ & MECÂNICA & INDIVIDUAL & $1,18 \times 10^{4}$ & $4,07^{\mathrm{e}}$ \\
\hline G & MANUAL & INDIVIDUAL & $1,20 \times 10^{3}$ & $3,08^{\mathrm{g}}$ \\
\hline $\mathrm{H}$ & MANUAL & COMUNITÁRIO & $5,80 \times 10^{5}$ & $5,76^{\mathrm{b}}$ \\
\hline I & MANUAL & COMUNITÁRIO & $2,93 \times 10^{7}$ & $7,46^{\mathrm{a}}$ \\
\hline $\mathrm{J}$ & MISTA & COMUNITÁRIO & $5,05 \times 10^{5}$ & $5,70^{\mathrm{b}}$ \\
\hline
\end{tabular}

*Amostras seguidas pela mesma letra não diferem estatisticamente entre si em relação à contagem de micro-organismos pelo teste de Duncan ao nível de significância de $5 \%$.

higiênicos, como frequência com que lava as mãos e o equipamento de ordenha, além da forma como são higienizados, muitas das vezes sem sanificantes adequados (Garboggini \& Gallo, 1998). A utilização de tanques de expansão comunitários também pode contribuir para o aumento da contaminação, onde através do compartilhamento de tanques, um produtor pode contaminar o leite de toda uma comunidade.

De forma geral, as amostras obtidas de tanques individuais e/ou ordenha mecânica apresentam uma qualidade microbiológica de bactérias aeróbias mesófilas e psicrotróficas superior àquelas obtidas em tanques comunitários e/ou ordenha manual (Figura 1). Observaram-se diferenças significativas $(\mathrm{p}<0,05)$ na contagem de bactérias aeróbias mesófilas e psicrotróficas nas amostras de tanques individuais e comunitários, cujas médias foram de 4,35 e 3,91 log UFC/mL e 6,41 e 6,30 $\log \mathrm{UFC} / \mathrm{mL}$, respectivamente. Da mesma forma, as amostras obtidas de ordenha mecânica apresentam contagens para ambos os grupos bacterianos inferiores $(4,35$ e 4,07 $\log \mathrm{UFC} / \mathrm{mL})$ às obtidas a partir de amostras de ordenha manual $(5,87$ e 5,50 $\log \mathrm{UFC} / \mathrm{mL})$.

\subsection{Coliformes totais e $\boldsymbol{E}$. coli}

De acordo com a tabela 3, apenas as amostras E e F não apresentavam coliformes totais (CT). Das 8 amostras contaminadas com CT, 6 delas apresentavam E. coli positiva, sendo elas as amostras B, D, G, H, I e J, o que representa uma contaminação de $60 \%$ do total de amostras coletadas. As fontes mais comuns de contaminação por esse grupo de bactérias são fezes de animais e resíduos do solo que podem contaminar o leite por meio da água utilizada na produção e higienização de superfícies, utensílios e equipamentos contaminados (Menezes et al., 2015).

Nas amostras dos 3 tanques de armazenamento comunitário avaliadas foram encontradas presença de CT e E. coli (Figura 2). A organização dos pequenos produtores em grupos ou associações que utilizam o tanque de refrigeração em conjunto foi a forma encontrada para reduzir custos, ganharem em escala e viabilizar a coleta a granel. Uma vez que o uso de tanques comunitários tem sido amplamente difundido, atendendo ao requisito de refrigeração, é importante conhecer a qualidade higiênica do leite armazenado nestas condições. Considerando que é reunida a matéria-prima de diversos produtores, a qualidade microbiológica é fundamental, pois é

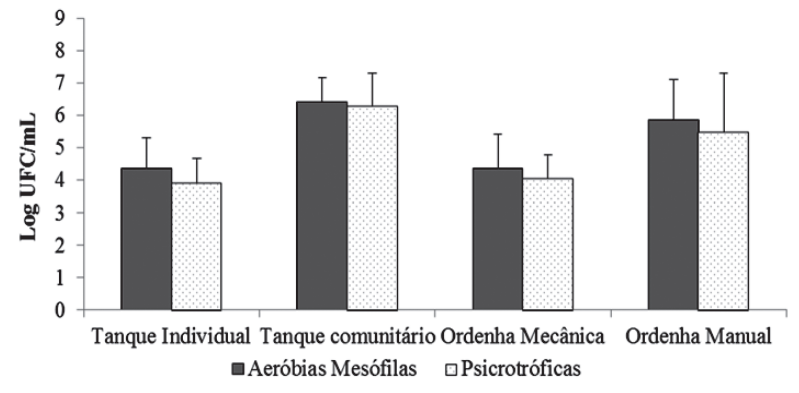

Figura 1 - Médias das contagens de bactérias aeróbias mesófilas e psicrotróficas em função do tipo de armazenamento e ordenha do leite cru coletado em propriedades da Zona da Mata de Minas Gerais. 
Tabela 3 - Avaliação da presença/ausência de coliforme totais e termotolerantes de amostras coletadas em tanques de refrigeração individuais e coletivos

\begin{tabular}{ccccc}
\hline AMOSTRA & ORDENHA & TANQUE & C TOTAIS & E. coli \\
\hline A & MECÂNICA & INDIVIDUAL & + & + \\
B & MECÂNICA & INDIVIDUAL & + & + \\
C & MECÂNICA & INDIVIDUAL & + & - \\
D & MECÂNICA & INDIVIDUAL & - & + \\
E & MECÂNICA & INDIVIDUAL & - & + \\
F & MECÂNICA & INDIVIDUAL & + & + \\
G & MANUAL & INDIVIDUAL & + & + \\
H & MANUAL & COMUNITÁRIO & + & + \\
I & MANUAL & COMUNITÁRIO & + \\
J & MISTA & COMUNITÁRIO & + \\
\hline
\end{tabular}

*Amostras seguidas pela mesma letra não diferem estatisticamente entre si em relação à contagem de micro-organismos pelo teste de Duncan ao nível de significância de $5 \%$.

determinada por fatores individuais de higiene, manejo e procedimentos de ordenha, que variam entre os diversos associados (Brito et al., 2003).

Nas quatro amostras obtidas a partir da ordenha manual também foram encontradas contaminação por CT e E. coli (Figura 2). A contaminação da amostra $\mathbf{J}$, de ordenha mista, pode ser considerada esperada por possuir possibilidades de contaminação tanto pela ordenha manual e quanto pela ordenha mecânica e, além disso, ser proveniente de um tanque de armazenamento comunitário, o que favorece a possibilidade de contaminação do leite. Números elevados de amostras de leite cru positivas para coliformes totais e E. coli indicam basicamente a falta de higiene na ordenha manual por parte do ordenhador ou limpeza inadequada dos utensílios que entram em contato com o leite. Para um processo de ordenha adequado existe

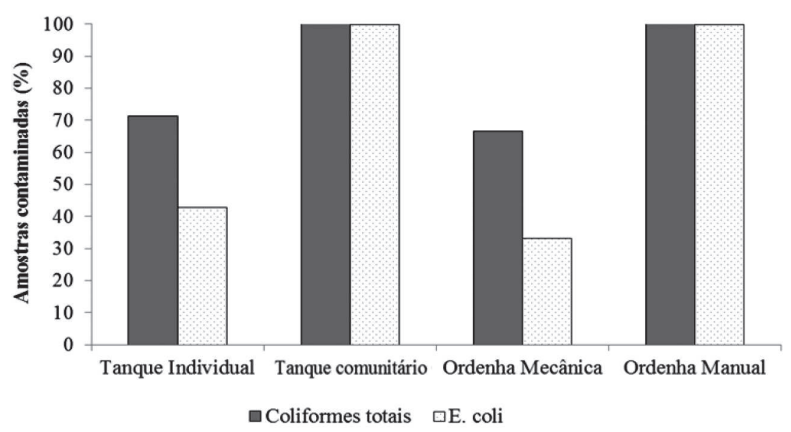

Figura 2 - Porcentagem de amostras positivas para coliformes totais e Escherichia coli em função do tipo de armazenamento e ordenha do leite cru coletado em propriedades da Zona da Mata de Minas Gerais. a necessidade de mão de obra qualificada, entretanto, talvez esse seja um dos principais problemas enfrentados pelos produtores de leite. Desta forma, com o intuito de diminuir despesas e mão de obra, muitos produtores de leite têm utilizado ordenhadeiras mecânicas em substituição a ordenha manual, associado à redução do tempo de trabalho, a praticidade e aumento da lucratividade. A ordenha manual ou mecânica influencia diretamente na qualidade do leite produzido, ou seja, a ordenha realizada de forma incorreta pode causar lesões no teto do animal que pode contribuir para a contaminação microbiológica do leite (Martins et al., 2005; Netto et al., 2009).

Coliformes termotolerantes, como E. coli, podem alcançar os tanques de refrigeração tanto via secreção intramamária como via contaminação fecal do úbere ou equipamentos utilizados na ordenha (Van Kessel, 2002). Quando avaliada a existência de contaminações de origem fecal, a bactéria analisada é $E$. coli, usada como indicador mais específico para esse tipo de análise, porque seria o único membro do grupo dos coliformes de origem exclusivamente fecal (Garboggini \& Gallo, 1998).

\section{CONCLUSÕES}

As condições higiênico-sanitárias de produção e armazenamento da maioria das amostras de leite cru refrigerado analisadas, não estão adequadas, o que pode estar relacionado à higienização deficiente que afeta a qualidade, durabilidade e segurança do produto. É evidente a necessidade de orientações técnicas aos produtores rurais para promover melhorias em todos os aspectos na produção leiteira. Tais orientações se 
fazem necessárias desde a ordenha, sendo ela manual ou mecânica, até o armazenamento em tanques de refrigeração.

\section{LITERATURA CITADA}

BAHOUT, A.A. Prevalence of Bacillus species in UHT milk. Association Veterinary

Medicine, v.42, p.47-53, 2000.

BRASIL. Ministério da Agricultura, Pecuária e Abastecimento. Instrução Normativa n. 51, de 18 de setembro de 2002. Departamento de Inspeção de Produtos de Origem Animal. Diário Oficial da União. Brasília, DF, 20 set.2002. Seção 1, p.13-22.

BRASIL. Ministério de Agricultura, Pecuária e Abastecimento. Instrução Normativa n. 62, de 29 de dezembro de 2011. Diário Oficial da União. Brasília, DF, 30 de dez de 2011. Seção 1.

BRASIL. Ministério da Saúde. Secretaria de Atenção à Saúde. Departamento de Atenção Básica. Guia Alimentar para a população brasileira: promovendo a alimentação saudável, 2006.

BRITO, M.A.V.P.; PORTUGAL, J.A.B.; DINIZ, F.H.; FONSECA, P.C.; ANGELO, F.F.; PORTO, M.A.C. Qualidade do leite armazenado em tanques de refrigeração comunitários. In: MARTINS, C.E.; FONSECA P.C.; BERNARDO W.F.; CÓSER A.C.; FRANCO P.R.V.; PORTUGAL J.A.B.; CARVALHO F.S. (Eds.). Alternativas tecnológicas, processuais e de políticas públicas para produção de leite em bases sustentáveis. Juiz de Fora: Embrapa Gado de Leite, p.21-43, 2003.

CERQUEIRA, M.M.O.P.; PAIVA, C.A.V.; LEITE, M.O.; FONSECA, L.M.; SOUZA, R.M.; PENNA, C.F.A.M. Impacto da qualidade da matéria-prima na indústria de laticínios, 2009. Acesso em: 24 ago. 2015. Disponível em: http:// multimedia.3m.com/mws/media/6859110/impactoqualidade-materia-prima.pdf

FONSECA, L.F.L.; SANTOS, M.V. Qualidade do leite e controle de mastite. São Paulo: Lemos Editorial, 2000.

FOSCHINO, R.; GALLI A.; OTTOGALLI, G. Research on the microflora of UHT milk. Annals of Microbiology, v.40, p.47-59, 1990.
FOX, P.F. The milk protein system in Developments. Em Dairy Chemistry-4. Functional milk proteins. Ed. Fox, P.F. Elsevier Applied Science Publishers Ltda, London and New York, p.1-53, 1989.

GARBOGGINI, I.L.A; GALLO, C.R. Pesquisa de Salmonella, Campylobacter, Coliformes totais e Escherichia coli em Águas de Nascentes (Bicas) em Piracicaba - SP. In: XVI Congresso Brasileiro de Ciências e Tecnologia de Alimentos, Rio de Janeiro. Anais 2, p.982-985, 1998.

GUERREIRO, P.K.; MACHADO, M.R.F.; BRAGA, G.C.; GASPARINO, E.; FRANZENER, A.S.M. Qualidade microbiológica de leite em função de técnicas profiláticas no manejo de produção. Ciências Agrotécnicas, v.29, n.1, p.216222, 2005.

IBGE. Estatística da Produção Pecuária. Aquisição de Leite. p.22-29, 2015. In: http:// www.ibge.gov.br. (acessado em 17 de Agosto de 2015).

IBGE. Indicadores IBGE $4^{\circ}$ trimestre de 2015. In: http://www.ibge.gov.br. (acessado em 02 de Junho de 2016).

MANFRIN SCABIN, K.E.; KOZUSNYANDREANI, D.I.; RODRIGUES FRIAS, D. F. Qualidade microbiológica do leite in natura durante o processo de obtenção e após o resfriamento. CES Medicina Veterinaria y Zootecnia, v.7, n.1, 2012.

MARTINS, A.G.L.A.; NASCIMENTO, A.R.; AMARAL, D.S.; MENDES FILHO, N.E.; OLIVEIRA, A.B. Evaluation of the contamination of the raw milk commercialized in the public roads of the city of Açailândia - MA by coagulase positive Staphylococcus. Revista Higiene Alimentar, v.30, n.256/257, p.9498, 2016.

MARTINS, E.S.; LIMA, C.M.F. Qualidade microbiológica de leite cru refrigerado obtido de propriedades rurais do município de Frutal MG: comparação das ordenhas mecânica e manual. Revista Brasileira de Tecnologia Agroindustrial, v.07, n.01, p. 955-964, 2013. 
MARTINS, M.L.; ARAÚJO, E.F.; MANTOVANI, H.C.; MORAES, C.A.; VANETTI, M.C. Detection of the apr gene in proteolytic psychrotrophic bacteria isolated from refrigerated raw milk.

Internanational Journal of Food

Microbiology, v.102, p.203-211, 2005.

MENEZES, I.R.; ALMEIDA, A.C.; MORÃO, R.P.; REISS, V.; SANTOS, C.A.; LOPES, I.L.N. Microbiological quality of raw milk produced in northern of Minas Gerais. Revista Brasileira de Ciência Veterinária, v.22, n.1, p.58-63, 2015.

NETTO, A.S.; FERNANDES, R.H.R.; AZZI, R.; LIMA, Y.V.R. Estudo comparativo da qualidade do leite em ordenha manual e mecânica.

Revista do Instituto de Ciências de Saúde, v.27, n. 9, p.345-349, 2009.

OLIVEIRA, C.A.F.; FONSECA, L.F.L.; GERMANO P.M.L. Aspectos relacionados à produção que influenciam a qualidade do leite. Revista Higiene Alimentar, v.13, n. 62, p.10-16, 1999.

PINHEIRO, A.J.R.; MOSQUIM, M.C.A.V. Processamento de leite de consumo. Viçosa, MG: UFV, 430p. 1991.

PINTO, C.L.O.; MARTINS, M.L.; VANETTI, M.C.D. Qualidade microbiológica de leite cru refrigerado e isolamento de bactérias psicrotróficas proteolíticas. Revista Ciência e Tecnologia de Alimentos, v.26, n.3, p.645-651, 2006.

SILVA, N.; JUNQUEIRA, V.C.A.; SILVEIRA, N.F.A.; TANIWAKI, M.H.; SANTOS R.F.S.; GOMES, R.A.R. Manual de métodos de análise microbiológica de alimentos e água. 4. ed. São Paulo: Varela, 2010.
SOMMERHAUSER, J.; KLOPPERT, B.; WOLTER, W.; ZSCHOCK, M.; SOBIRAJ, A.; FAILING, K. The epidemiology of Staphylococuus aureus infections from subclinical mastitis in dairy cows during a control programme. Veterinary Microbiology, v.96, n.1, p.91-102, 2003.

SOUTO, L.I.M.; SAKATA, S.T.; MINAGAWA, C.Y.; TELLES, E.O.; GARBUGLIO, M.A.; BENITE, N.R. Qualidade higiênico-sanitária do leite cru produzido em propriedades do estado de São Paulo, Brasil. Arquivo Brasileiro de Medicina Veterinária e Zootecnia, v.16, n.3, p.491-499, 2009.

TAVOLARO, P.; OLIVEIRA, C.A.F.; LEFÈVRE, F. Avaliação do conhecimento em práticas de higiene: uma abordagem qualitativa. Revista Interface, v. 10, n. 19, 2006.

TEBALDI, V.M.R.; OLIVEIRA, T.L.C.; BOARI, C.A.; PICCOLI, R.H. Isolamento de coliformes, estafilococos e enterococos de leite cru provenientes de tanques de refrigeração por expansão comunitários: identificação, ação lipolítica e proteolítica. Ciência e Tecnologia de Alimentos, v.28, n.3, p.753-760, 2008.

VAN KESSEL, J.S.; NEDOLUHA, P.C.; WILLIAMS-CAMPBELL, A.; BALDWIN, R.L.; MCLEOD, K.R. Effects of ruminal and postruminal infusion of starch hydrolysate or glucose on the microbial ecology of the gastrointestinal tract in growing steers. Journal of Animal Science, v.80, n.11, p.3027-3034, 2002.

VIDAL-MARTINS, A.M.C.; ROSSI, J.R.O.D.; REZENDE-LAGO, N.C. Microrganismos heterotróficos mesófilos e bactérias do grupo do Bacillus cereus em leite integral submetido a ultra-alta temperatura. Arquivo Brasileiro de Medicina Veterinária e Zootecnia, v.57, n.3, p.396-400, 2005.

WALSTRA, P.; WOUTERS, J.T.M.; GEURTS, T.J. Dairy science and technology. New York: CRC, p.166-167, 2006.

Recebido para publicação em 6/1/2017 e aprovado em 28/3/2017. 